\title{
sciendo THE EFFECTS OF THE ADDITION OF VEGETABLE OIL ON THE VISCOSITY OF USED MARINE ENGINE OIL MARINOL RG 1240
}

DOI 10.2478/ntpe-2018-0059

\author{
Mgr inż. Małgorzata Malinowska \\ Gdynia Maritime University, Poland \\ 2018 \\ Volume 1 \\ Issue 1 \\ pp. $479-485$
}

\begin{abstract}
The article presents conducted research on the effects of the additives of vegetable oil on the viscosity of used marine engine oil Marinol RG 1240. Specifically, it shows dependence between viscosity and temperature for: fresh mineral oil, used mineral oil and blends of oils. Research results were compared and assessed. The viscosity of all oil samples were measured using Vibro Viscometer $\mathrm{SV}-10$, at range of temperatures $5^{\circ} \mathrm{C}-65^{\circ} \mathrm{C}$. It is noted that most of the used engine oil samples increase value of viscosity compared to fresh oil. However, the addition of $10 \%$ rapeseed oil significantly reduced viscosity parameters for all studied temperatures.
\end{abstract}

Keywords: vegetable oil, engine oil, rapeseed oil, mineral oil, marine

\section{INTRODUCTION}

Nowadays, It is necessary the tightening of environmental requirements, due to the inexorable exhaustion of fossil-fuel reserves, particularly oil and growing environmental pollution. In particular, this problem concerns fuels and engine oils used in transport. In this article focused only on marine lubricating oil because they play an important role for energy efficiency of ship as they are directly involved with frictional force and components wear characteristics (Kalam et al., 2017)

Among all lubricants used, the mineral oils are most popular. They represent $90 \%$ of world production of all type of lubricants due to their easy availability and low price. Unfortunately, they have many disadvantages and the most important are: low biodegradability, toxicity, and the polycyclic aromatic hydrocarbons contained therein may be mutagenic and carcinogenic in contact with the skin of animals or humans and may adversely affect the world of plants.

The solution can be products of natural origin, it is mean the natural oils which are biodegradable and non-toxic. The raw material base for the production of biodegradable lubricants can be fats, both animal and plant. Green oils have good lubricity and viscosity properties, show high shear resistance, do not corrode, and also very well mix with mineral oils (Malinowska, 2017).

Vegetables oils can already be found in the food industry, forestry, agriculture and environmental sectors. They are used as lubricants for tractors and other agricultural machinery, gear oils, hydraulic fluids, lubricating oils for chain saws, metalworking fluids and industrial lubricants (Erhan and Asadauskas, 2000).

In Poland, from the group of vegetable oils, the most common lubricant is rapeseed oil, modified by epoxidation to improve thermal and oxidative stability (Erhan and Asadauskas, 2000). Therefore, rapeseed oil was selected for research.

\section{VISCOSITY}

The viscosity of a fluid is a measure of its resistance to flow. It is the measure of internal friction in a fluid, which acts as a resistance to change of molecule position in moving fluid exposed to shear stress (Ljubas, 2010). Viscosity, alongside TBN (Total Base Number) and 
flash point, is the most significant physicochemical indices of marine engine oil (Malinowska, 2016).

The viscosity affects the lubrication quality during mixed friction as well as the opportunity to create and maintain hydrodynamic conditions for fluid friction depends on it. The proper viscosity of oil allows protecting critical components, provide reliable operation, lower maintenance costs, decrease downtime, increase equipment life. In short, it results efficiency, durability and reliability of engine. The viscosity of lubricating oils depends on the temperature and load-speed modes of their operation. Engine oils with high viscosity operate better at low speeds, high loads, and elevated temperatures. However, for high speeds, low loads, and low temperatures of operation of friction units, preference is given to oils with low viscosity(Malinowska, 2016, Markova, 2010).

Another important feature is that viscosity of oil changes during the exploitation process may increase or decrease. Any changes are undesirable in an engine as they affect the lubrication effectiveness. The viscosity changes along with, (Malinowska, 2016, Markova, 2010, Krupowies, 2009, Speight, 2015):

- temperature - for mineral oil, it increases significantly while the temperature rises. The rise of temperature causes the increase distance between molecules which results in the decrease of coherence force and accordingly internal friction force;

- pressure - the viscosity of oil increases as pressure grows, and the change follows an exponential curve. The growth caused by the approach of liquid particles, and the increase of intermolecular interactions;

- shear rate - dependency is the effect of the type of property that the oil exhibits, whether it behaves like a Newtonian fluid or a Non-newtonian fluid;

- contamination - two cases (Hasannuddin, 2016):

- formation of resinous products because of oil oxidation, evaporation of lighter fractions, depletion of anti-wear additives and contamination by insoluble compounds tend to increase viscosity;

- moisture addition, fuel dilution and shearing of viscosity index improvers tend to reduce the oil viscosity.

Due to such a large influence of various factors on the viscosity (temperature, pressure, contamination etc.) is important not only to proper choose the type of oil but also to monitor the viscosity. Every excessive increase or decrease in the viscosity can result permanent modifications of characteristics of oil, as a consequence the interference or destroy lubricating system of engine. For example during sea voyage it is critical situation.

a)

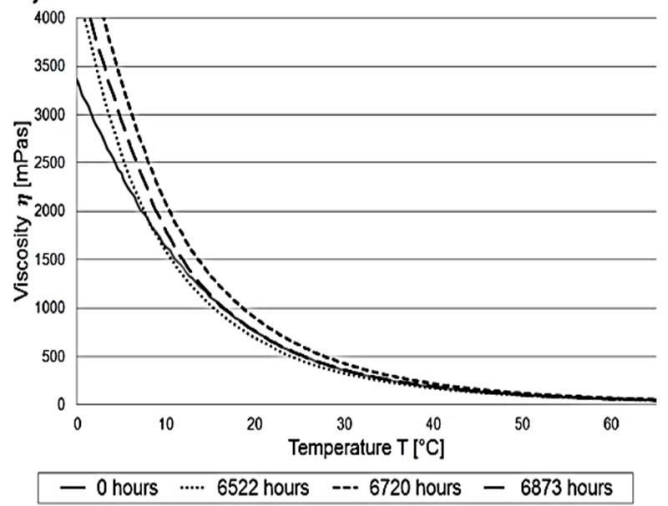

b)

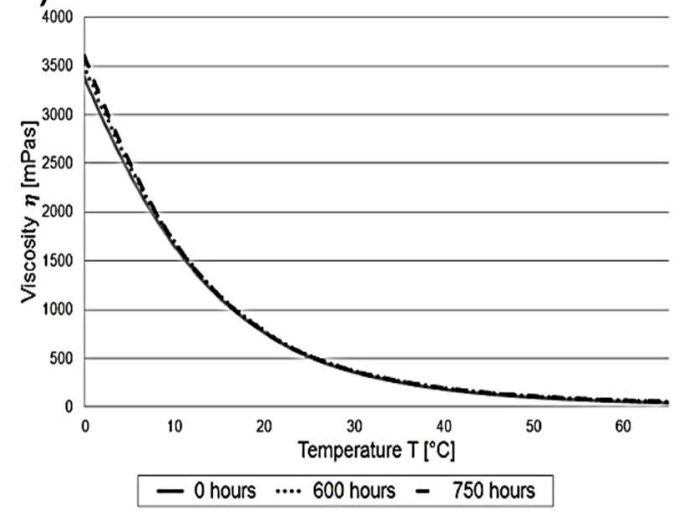

Fig. 1. The graph of viscosity-temperature changes for Marinol RG 1240 after different time of usage in:

a) auxiliary marine engine Cegielski-Sulzer 6AL20/24 of $410 \mathrm{~kW}$;

b) laboratory marine engine Cegielski-Sulzer 3AL25/30 of 408 kW

The Figure 1a. and b. present viscosity-temperature changes for engine oil Marinol RG 1240 after different working times in two different marine engines: Cegielski-Sulzer 6AL20/24 of 410 
kW and Cegielski-Sulzer 3AL25/30 of 408 kW (Malinowska, 2016). In all tested samples, the viscosity of oil increases along with the consumption.

If a little change in the oil viscosity is detected, further analysis of the oil can identify the cause of the disturbance of its properties. High viscosity value in oil indicates that contamination or oxidation are deteriorating the lubricant, whereas, low viscosity value indicates decrease in the dilution property of the oil. Variation in the oil viscosity is often the first indicator of a global problem of the tribological unit (Malinowska, 2016, Markova, 2010, Erhan et al, 2006).

\section{VEGETABLE OILS}

The vegetable oils also called green oils, biolubricants or natural esters. They can originate from very different natural source, for example: sunflower, rapeseed, palm oil, coconut etc. It is almost 350 oil-bearing crops available all over the world (Kalam et al., 2017). Natural oils are mainly triglycerides which contain three hydroxyl groups and long chain unsaturated free fatty acids attached at the hydroxyl group by ester linkages (Fox and Stachowiak, 2007, Shahabuddin et al., 2013) These triglycerides molecules in vegetable oils orient themselves with the polar end at the solid surface making a closed packed monomolecular or multimolecular layer resulting in a surface film that provides desirable qualities in a lubricant (Asadauskas et al., 1997).

The green oils as lubricants, have a lot of advantages, the most important are: biodegradable, non-toxic, excellent temperature - viscosity properties, include very low volatility due to the high molecular weight of the triglyceride molecule, good lubricity, because their polar ester groups are able to adhere to metal surfaces, and therefore, have high solubilizing power for polar contaminants and additive molecules, blends well with the other type of oils, non-reacts with sealing materials, high flash and fire point (Malinowska, 2017, Erhan et al, 2006, Jóźwiak and Szlęk, 2006, Rudnicki, 2002).

However, green oils also have certain drawbacks: characterized by limited thermal and oxidative stability and low hydrolytic stability, poor corrosion protection, gumming effect, high frictional coefficient, high pour point etc. They oxidize at lower temperatures than mineral oils. But, thanks to the wide content of unsaturated free acids, it is possible to adapt vegetable oils to be used as substitutes for mineral oils in the production of lubricants, by means of genetic engineering (regulation of plants cultivation) or chemical modification (Kozdrach, 2016, Szłajko and Fiszer, 2003).

The author chose rapeseed oil, because is the most popular oil in Poland among a large group of vegetable lubricants. The polar nature of rapeseed oil make good lubricants, as they readily fasten to metal surfaces. The triglyceride structure gives these esters a high natural viscosity and viscosity index (Karcz et al., 2006). Basic parameters of rapeseed oil presents in Table 1 (Malinowska, 2017).

Table 1.

Parameters of vegetable oil - rapeseed oil.

\begin{tabular}{|c|c|c|c|c|}
\hline No. & Requirements & Research methods & Unit & $\begin{array}{c}\text { Rapeseed } \\
\text { oil }\end{array}$ \\
\hline & density & & $\mathrm{kg} / \mathrm{m}^{3}$ & 902 \\
\hline 1 & kinematic viscosit at $100^{\circ} \mathrm{C}$ & PN-EN ISO 3104:2004 & $\mathrm{mm}^{2} / \mathrm{s}$ & 7.5 \\
\hline & kinematic viscosity at $40^{\circ} \mathrm{C}$ & PN-EN ISO $3104: 2004$ & $\mathrm{~mm}^{2} / \mathrm{s}$ & 33.9 \\
\hline 2 & pour point & ASTM D-5950 & ${ }^{\circ} \mathrm{C}$ & -20 \\
\hline 3 & flash point & PN-ISO 2909:2009 & & $>300$ \\
\hline 5 & viscosity index & & $\mathrm{mg} \mathrm{KOH} / \mathrm{g}$ & 192 \\
\hline \multicolumn{2}{|l|}{} \\
\hline
\end{tabular}

Source: Malinowska, 2017, Jóźwiak and Szlęk, 2006, Kozdrach, 2016

Early has been investigated the possibility of adding rapeseed oil to fresh mineral engine oil Marinol RG 1240 in different quantity (Malinowska, 2017). The research showed that "The very important property of vegetable oil it is smaller viscosity change in the range of tested temperatures (Fig. 2) [...]. This behavior is transferred to all blends of rapeseed oil and mineral oil Marinol RG 1240, the change of viscosity in temperature range investigated decreases 
along with content of rapeseed oil [...]. The insignificant impact of the plant additives up to $10 \%$, can be used economically. Engine operators can make small refills of lubricating system with vegetable oils without worrying about its influence on the of mineral oil viscosity" (Malinowska, 2017).

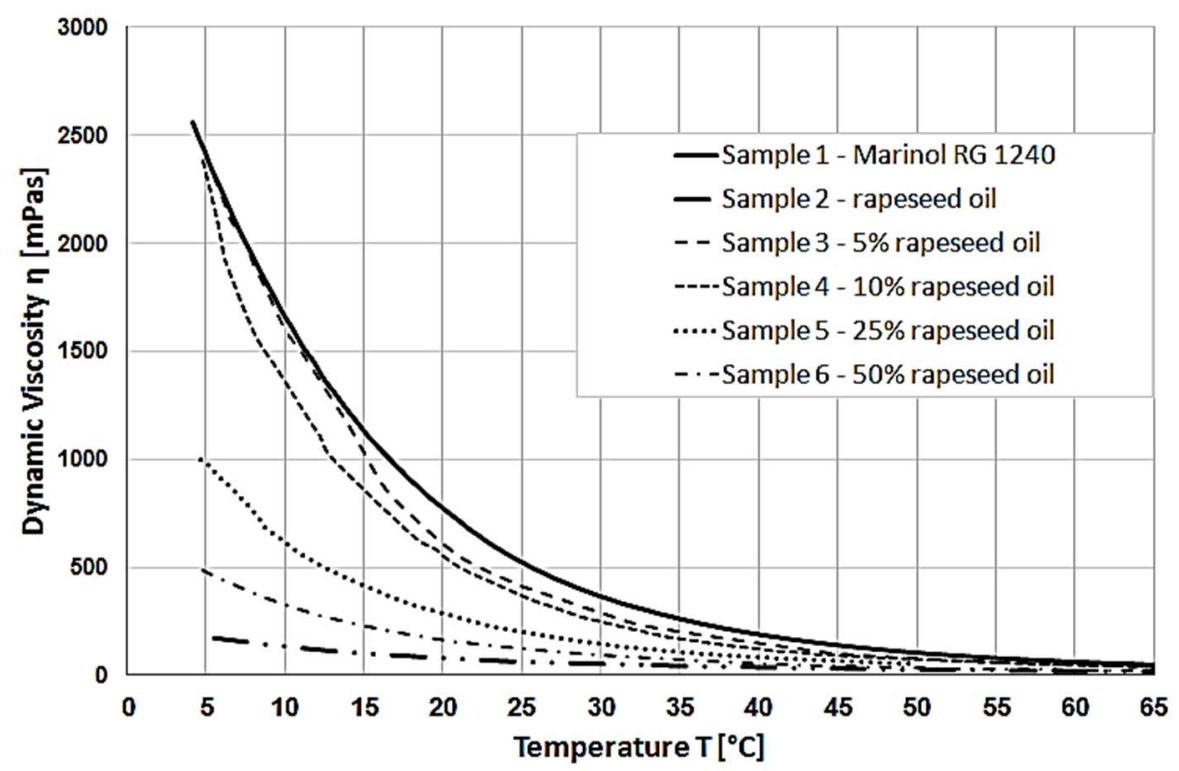

Fig. 2. The graph of viscosity-temperature changes for different blends of fresh Marinol RG 1240 and rapeseed oil.

Source: Malinowska, 2017

\section{EXPERIMENT}

The research was conducted using engine oil of Lotos Company - Marinol RG 1240. Marine motor oil Marinol RG 1240 is TPEO (Trunk Piston Engine Oil) and it is designed for lubrication of marine anhydride light fuel engines (Lotosoil.pl, 2017). This engine oil has been mixed with rapeseed oil.

The dynamic viscosity of all oil samples were measured using Vibro Viscometer SV-10, at range of temperatures $5^{\circ} \mathrm{C}-65^{\circ} \mathrm{C}$. The device has 2 thin sensor plates that are driven with electromagnetic force at the same frequency by vibrating at constant sine-wave vibration in reverse phase like a tuning fork. Viscometer can measurement from very low to high viscosity in the range $0.3-1000 \mathrm{mPas}$.

In the first phase of study, attention was paid to the behavior of viscosity of used samples of marine motor oil Marinol RG 1240. On the basis of the graphs presented in the chapter "Viscosity" (Fig. 1) It has been designated the percentage difference between the viscosity of used samples oil and the viscosity of fresh engine oil in selected temperatures $\left(5^{\circ} \mathrm{C}, 10^{\circ} \mathrm{C}\right.$, $20^{\circ} \mathrm{C}, 40^{\circ} \mathrm{C}$ and $60^{\circ} \mathrm{C}$ ). Thanks to that, it was possible to determine trends of viscosity changes for marine engine oil. Results were summarized into the tables: for engine Cegielski-Sulzer 6AL20/24 in Table 2 and for engine Cegielski-Sulzer 3AL25/30 in Table 3.

It can be noted that most of the engine oil samples increase value of viscosity compared to fresh oil Marinol RG 1240. The largest change was observed in sample from engine CegielskiSulzer 6 AL20/24 after 6720 hours at $5^{\circ} \mathrm{C}$, it is increase by $37.8 \%$. The samples from engine Cegielski-Sulzer 6AL20/24 after 600 and 750 hours have an only minor change, to several percentages. This is due to a short period of work. 
Table 2.

The viscosity for selected temperatures for used oil samples Marinol RG 1240 in marine engine Cegielski-Sulzer 6AL20/24.

\begin{tabular}{|l|c|c|c|c|c|}
\hline \multicolumn{1}{|c|}{ Samples } & $\mathbf{5}^{\mathbf{}} \mathbf{C}$ & $\mathbf{1 0}^{\circ} \mathbf{C}$ & $\mathbf{2 0}^{\circ} \mathbf{C}$ & $\mathbf{4 0}^{\circ} \mathbf{C}$ & $\mathbf{6 0}^{\circ} \mathbf{C}$ \\
\hline fresh Marinol RG 1240 [mPas] & 2399 & 1628 & 764 & 181.3 & 59 \\
\hline 6522 hours [mPas] & 2693 & 1496 & 686 & 172.6 & 60 \\
\hline change the viscosity [\%] & 12.3 & -8.1 & -10.2 & -4.8 & 1.7 \\
\hline 6720 hours [mPas] & 3306 & 1778 & 760 & 185.5 & 72.5 \\
\hline change the viscosity [\%] & 37.8 & 9.2 & -0.5 & 2.3 & 22.9 \\
\hline 6873 hours [mPas] & 2991 & 2042 & 886 & 218.1 & 62 \\
\hline change in viscosity [\%] & 24.7 & 25.4 & 16 & 20.3 & 5.1 \\
\hline
\end{tabular}

Table 3.

The viscosity for selected temperatures for used oil samples Marinol RG 1240 in marine engine Cegielski-Sulzer 3AL25/30.

\begin{tabular}{|l|c|c|c|c|c|}
\hline \multicolumn{1}{|c|}{ Samples } & $\mathbf{5}^{\mathbf{}} \mathbf{C}$ & $\mathbf{1 0}^{\circ} \mathbf{C}$ & $\mathbf{2 0}^{\circ} \mathbf{C}$ & $\mathbf{4 0}^{\circ} \mathbf{C}$ & $\mathbf{6 0}^{\circ} \mathbf{C}$ \\
\hline fresh Marinol RG 1240 [mPas] & 2399 & 1628 & 764 & 181,3 & 59 \\
\hline 600 hours [mPas] & 2490 & 1655 & 779,8 & 191,5 & 63 \\
\hline change in viscosity [\%] & 3.8 & 1.7 & 2.1 & 5.6 & 6.8 \\
\hline 750 hours [mPas] & 2511 & 1683 & 775.2 & 191.7 & 64 \\
\hline change in viscosity [\%] & 4.7 & 3.4 & 1.5 & 5.7 & 8.5 \\
\hline
\end{tabular}

Following previous studies and analyzing the graph (Fig. 2) in the chapter "Vegetable oil", it can be seen that the addition of rapeseed oil reduces viscosity throughout the temperature range. Based on these conclusions, it was decided to add rapeseed oil to sample after 6873 working hours in the marine engine Cegielski-Sulzer 6AL20/24. The amount of additive was set at $10 \%$, due to its small effect on viscosity behavior (Fig. 2). In second sample added $10 \%$ fresh motor oil Marinol RG1240, for comparative purposes. The compositions of samples are shown in the Table 4, and the resulting values of viscosity in the Table 5.

Table 4.

Composition of tested oils.

\begin{tabular}{|c|c|}
\hline Samples & Composition \\
\hline Sample 1 & $90 \%$ Marinol RG 1240 after 6873 hours working and 10\% rapeseed oil \\
\hline Sample 2 & $90 \%$ Marinol RG 1240 after 6873 hours working and 10\% fresh Marinol RG 1240 \\
\hline
\end{tabular}

Table 5.

The viscosity for selected temperatures for sample 1 and sample 2.

\begin{tabular}{|l|c|c|c|c|c|}
\hline \multicolumn{1}{|c|}{ Samples } & $\mathbf{5}^{\circ} \mathbf{C}$ & $\mathbf{1 0}^{\circ} \mathbf{C}$ & $\mathbf{2 0}^{\circ} \mathbf{C}$ & $\mathbf{4 0}^{\circ} \mathbf{C}$ & $\mathbf{6} \mathbf{0}^{\circ} \mathbf{C}$ \\
\hline fresh Marinol RG 1240 [mPas] & 2399 & 1628 & 764 & 181.3 & 59 \\
\hline sample 1 [mPas] & 1740 & 1130 & 498 & 112 & 53.1 \\
\hline change in viscosity [\%] & -27.5 & -30.6 & -34.8 & -38.2 & -10 \\
\hline sample 2 [mPas] & 2630 & 1510 & 616 & 152 & 58.7 \\
\hline change in viscosity [\%] & 9.6 & -7.2 & -19.4 & -16.2 & -0.5 \\
\hline
\end{tabular}

As can be seen, the addition of $10 \%$ rapeseed oil significantly reduced viscosity parameters for all temperatures. For temperatures $5^{\circ} \mathrm{C}, 10^{\circ} \mathrm{C}, 20^{\circ} \mathrm{C}$ and $40^{\circ} \mathrm{C}$ by more than $50 \%$ and for $60^{\circ} \mathrm{C}$ by $15.1 \%$ in relation to oil sample after 6873 working hours. The effect of this additive on the used oil is much greater than on the fresh marine engine oil (Fig. 2). This is an unexpected effect. It should be emphasized that the addition of fresh Marinol RG 1240 achieves similar result, a maximum change of $36.5 \%$ at $40^{\circ} \mathrm{C}$. The problem is extremely interesting, so it is planned to continue the research. In the next steps of investigation, particular attention will be paid to other parameters, especially TBN and the lubricity properties and other vegetable oils, such as sunflower, coconut, peanut, grape seed, olive etc. 


\section{CONCLUSION}

The modern exploitation liquids must be easily biodegradable and ecology. One of the most popular solutions which are environmental friendly, they are products of natural origin.

In this article, the effects of the additive of vegetable oil on the viscosity of used marine engine oil Marinol RG 1240 researched. Among very huge group of green oils chosen the rapeseed oil, which is a most popular in Poland. The viscosity of rapeseed oil behaves like viscosity of conventional mineral oil. Furthermore, the change of viscosity with temperature is much less for this green oils. The possibility of better lubricating performance of rapeseed oil has high potential for use as a marine engine lubricating oil for improving efficiency of them. The addition of $10 \%$ rapeseed oil significantly reduced viscosity parameters for whole range of temperature. Unfortunately, biolubricants have a lot drawbacks, for examples they characterized by limited thermal and oxidative stability and low hydrolytic stability, poor corrosion protection, gumming effect, high frictional coefficient etc. However, it is possible improved them by chemical modification like epoxidation, hydrogenation and adding antioxidants.

The introduction of a wide range of bio-renewable lubricants will contribute to a better use of vegetable oils in place of toxic mineral oils. However, this requires developing a biodegradable oil base. Therefore, in the next step of the measurements, it is planned to check TBN, lubricity properties, hydrolytic stability, oxidation stability etc. of rapeseed oil and its blends with fresh and used mineral oil. Then to investigate other vegetable oils, such as sunflower, coconut, peanut, grape seed, olive and select the one that best will fulfill the tasks of marine engine oil.

\section{REFERENCES}

Kalam, M.A., Masjuki, H.H., Haeng, Muk Cho, Mosarof, M.H., Md. Iqbal Mahmud, Mohammad Asaduzzaman Chowdhury, Zulkifli, N.W.M. (2017) Influences of thermal stability, and lubrication performance of biodegradable oil as an engine oil for improving the efficiency of heavy duty diesel engine. Fuel, 196, pp. 36-46.

Malinowska, M. (2017) The full or partial replacement of mineral marine engine oil with vegetable oil, on the example of rapeseed oil. Journal of KONES, 24, 1, pp. 247-255.

Erhan S.Z., Asadauskas S. (2000) Lubricant basestocks from vegetable oils. Industrial Crops and Products., 11, pp. 277-282.

Ljubas, D., Krpan, H., Matanović, I. (2010) Influence of engine oils dilution by fuels on their viscosity, flash point and fire point. Nafta: Exploration, Production, Processing, Petrochemistry, 61(2), pp. 73-79.

Malinowska, M.(2016) Assessment of the degree of deterioration of trunk piston engine oil used in the engine 6 AL20/24. Journal of KONES, 23, 4, pp. 319-326.

Markova, L.V., Makarenko, V.M., Semenyuk, M.S., Zozulya, A.P. (2010) On-line monitoring of the viscosity of lubricating oils. Journal of Friction and Wear, 31, 6, pp. 433-442.

Krupowies. J. (2009) Badania i ocena zmian właściwości użytkowych olejów urządzeń okrętowych. Wydawnictwo Naukowe Akademii Morskiej w Szczecinie, Studia Nr 49., Szczecin.

Speight J.G. (2015) Handbook of Petroleum Product Analysis. A John Wiley \& Sons Inc., Hoboken, New Jersey.

Hasannuddin, AK., Wira, JY., Sarah, S., Wan Syaidatul Aqma, WMN., Rahman, A.H.A., Hirofumi, N., Aizam, SA., Aiman, MAB., Watanabe, S., Ahmad, MI., Azrin, MA. (2016) Performance, emissions and lubricant oil analysis of diesel engine running on emulsion fuel. Energy Conversion and Management, 117, pp. 548-557.

Erhan, S.Z., Sharma, B.K., Perez, J.M. (2006) Oxidation and low temperature stability of vegetable oil-based lubricants. Industrial Crops and Products, 24, 3, pp. 292-299.

Fox N., Stachowiak, G. (2007) Vegetable oil-based lubricants - a review of oxidation. Tribol., 40, pp. $1035-1046$.

Shahabuddin, M., Masjuki, H.H., Kalam, M.A., Bhuiya, M.M.K., Mehat, H. (2013) Comparative tribological investigation of bio-lubricant formulated from a non-edible oil source (Jatropha oil). Industrial Crops and Products, 47, pp. 323-330.

Asadauskas, S., Perez, J.M, Duda, J.L. (1997). Lubrication properties of castor oil -Potential base stock for biodegradable lubricants. Lubrication Engineering, 53, pp. 35-40.

Jóźwiak, D., Szlęk, A. (2006) Ocena oleju rzepakowego jako paliwa kotłowego. Energetyka, 6, pp. 449-451. 
Rudnick, L.R. (2002) A comparison of synthetic and vegetable oil esters for use in environmentally friendly fluids. Erhan, S.Z., Perez, J.M. (Eds.) Bio-based Industrial Fluids and Lubricants. AOCS Press, Champaign, pp. 20-34.

Kozdrach, R. (2016) The influence of different vegetable dispersion phases on the rolling contact fatigue of biodegradable lubricating greases. Tribol., 6, pp. 57-67.

Szłajko U., Fiszer S. (2003) Modyfikacja chemiczna olejów roślinnych w aspekcie ich wykorzystania w produkcji paliw silnikowych i środków smarowych. Przemysł Chemiczny, 82, 1, pp. 18-21.

Karcz, H., Kosiorek, A., Butmankiewicz, J., Maciejak, D. (2006) Możliwość opalania kotłów energetycznych roztworem wodnym mieszanek oleju rzepakowego z olejami ropopochodnymi. Energetyka i ekologia, pp. 699-707.

Lotosoil.pl (2017) www.lotosoil.pl/resource/show/14718.pdf (accessed 15 May 2017).

Date of submission of the article to the Editor: 06/2018

Date of acceptance of the article by the Editor: 08/2018 